\title{
Acute Impact of the Artificial Sweetener Aspartame on the Ultrastructures of Hepatocyte in Mice
}

\author{
Norah S. Al-Johani1, Ayoub A. Bazzaz ${ }^{2 *}$ \\ ${ }^{1}$ Department of Biology, Faculty of Science, University of Taibah, Al-Madina Al-Munawara, KSA \\ ${ }^{2}$ Department of Basic Science, Faculty of Dentistry, University of Kerkuk, Kerkuk, Iraq \\ Email: ^ayoubbazzaz@yahoo.co.uk
}

How to cite this paper: Al-Johani, N.S. and Bazzaz, A.A. (2019) Acute Impact of the Artificial Sweetener Aspartame on the Ultrastructures of Hepatocyte in Mice. Advances in Bioscience and Biotechnology, 10, 165-177.

https://doi.org/10.4236/abb.2019.106012

Received: April 29, 2019

Accepted: June 27, 2019

Published: June 30, 2019

Copyright $\odot 2019$ by author(s) and Scientific Research Publishing Inc. This work is licensed under the Creative Commons Attribution International License (CC BY 4.0).

http://creativecommons.org/licenses/by/4.0/

\section{cC) (7) Open Access}

\begin{abstract}
A non-saccharide artificial sweetener, aspartame (L-aspartyl-L-phenylalanine methyl ester) is used worldwide as a sugar substitute in many foods and beverages. The objective of this work was to clarify the acute impact of various doses of daily ingestion of Aspartame at the cellular level of the liver tissues in mice. Sixty adult male mice were divided into five groups including control fed normal diet and tap water, while other 4 groups (12 each) were daily fed orally with $1 \mathrm{~mL}$ of either 40,500, 1000 and $1500 \mathrm{mg} / \mathrm{Kg}$ b.wt. APM dissolved in distilled water using gavages for consecutive 5 weeks. Liver samples fixed in $10 \%$ formalin were cut as $5 \mu \mathrm{m}$ using Leica microtome and the sections were stained with both routine Heamatoxylene and Eosin (H \& E) as well as Transmission electron Microscope (TEM). Histological results showed cellular changes in the hepatic tissues which were proportional with the increased doses. The hepatocytes had developed fatty droplets in the cytoplasm of almost all cells, loss of nuclei, necrosis detectable at LM level. Lymphatic nodules were also generated around the triads and the central hepatic veins as well as intracellular gaps with higher doses. The TEM results demonstrated degradation of mitochondria indicating the direct acute effects of the aspartame on hepatic tissues which all were proportional with the increased doses. It is concluded that the daily ingestion of aspartame, even at lower doses, has acute effects and is dose dependant on hepatic cells which could exert further risks onto other tissues of consumers on the long run.
\end{abstract}

\section{Keywords}

Acute Effects, Aspartame, Cirrhosis, Hepatocytes, Mice 


\section{Introduction}

Aspartame (APM), the most rigorously ever tested food ingredients and the most popular artificial sweeteners available in the market sold under the brand names NutraSweet and Equal is used widely in packaged products, e.g. labeled as "diet" foods [1]. Upon administrated the APM will soon be metabolized in the gastro intestinal tract into three components, the amino acids, aspartic acid (Asp) and phenylalanine (Phe) and methanol [2]. These components are promptly released within the upper gastrointestinal tract (GIT) by enzymatic action and may also be absorbed by intestinal mucosal cells where it is hydrolyzed to its components, transported across the wall of the small bowel and finally go through the general systemic circulation [3]. Therefore, blood will be the station which receives these components to carry them across to the next station that is the liver. While Aspartic acid is produced by the body, the phenylalanine is an essential amino acid that body gets it from food. Although the safety of aspartame has been studied since its discovery in 1965 [4], it does face real controversy in recent years i.e. many opponents have claimed that it is actually bad for the health. Although, aspartame has been claimed to be safe for human consumption by more than ninety countries worldwide [5] [6]; however, as for 2017 evidence does not support a benefit for weight loss or in diabetes with some data finding an association with weight gain and heart disease risks [7] [8]. The Food and Drug Administration (FDA) officials described aspartame as one of the most thoroughly tested and studied food additives while the agency has approved its safety as "clear cut" but has been the subject of several controversies, hoaxes [9] [10] and health scares [11].

The metabolism of aspartame in the body yields methanol which is toxic in large quantities, yet smaller amounts may also be concerning when combined with free methanol because of enhanced absorption. Free methanol is present in some foods and is also created when aspartame is heated. Free methanol consumed regularly may be a problem because it breaks down into formaldehyde, a known carcinogen and neurotoxin, in the body [12]. However, the Food Standards Agency (FDA) in the United Kingdom states that even in children who are high consumers of aspartame, the maximum intake level of methanol is not reached. They also state that since eating fruits and vegetables is known to enhance health, methanol intake from these sources is not a high priority for research. Aspartame found in commercial products or heated beverages may be a seizure trigger and should be evaluated in cases of difficult seizure management [13].

A number of regulatory agencies and health-related organizations i.e. USA Food and Drug Administration (FDA); United Nations Food and Agriculture Organization, World Health Organization (WHO), American Heart Association and American Dietetic Association have weighed in favorably on aspartame. In 2013, the European Food Safety Authority (EFSA) concluded a review of more than 600 data sets from aspartame studies and found no reason to remove as- 
partame from the market. The review reported no safety concerns associated with normal or increased intake.

The acute impact of the artificial sweetener aspartame on blood parameters of mice has shown considerable changes [14]. However, studies on the cellular level to demonstrate the impact of Aspartame on some body organs, liver are so scanty. The objective of the present study has been to demonstrate the acute effects of daily ingestion of various doses of aspartame on hepatic cells in mice via both light (LM) and transmission electron microscope (TEM).

\section{Materials and Methods}

\subsection{Aspartame (APM)}

With chemical structure [CAS No. 22839-47-0, the Synonyms N-L- $\alpha$-AspartylL-phenylalanine1-Methyl Ester, H-Asp-Phe-OMe and Chemical Formula of $\mathrm{C}_{14} \mathrm{H}_{18} \mathrm{~N}_{2} \mathrm{O}_{5}$ ] was obtained from a Japanese Company, Tokyo Chemical Industry Co (TCI) as a fine white powder of $25 \mathrm{gm}$ per bottle with purity of $98 \%$.

\subsection{Preparation of Aspartame Doses}

Four concentrations were prepared: 40, 500, 1000 and $1500 \mathrm{mg} / \mathrm{Kg}$ b.wt by dissolving correct amount in weight of the aspartame in distilled water in a lidded glass bottle adequate to cover 12 experimental mice a time per day for each dose.

\subsection{Animal and Animal Care}

Sixty male Albino Swiss Webster (SW) mice of two months old weighing (22 \pm 2 gm) obtained from King Saud University, Riyadh, KSA, were encountered in this project. They were housed as 6 per cage for approximately 5 days prior to the beginning of the study. All animals had free access to both diet and water and were maintained on a 12:12 light:dark exposure schedule throughout the study while the atmosphere of the animal colony was maintained at $\left(24^{\circ} \mathrm{C} \pm 2^{\circ} \mathrm{C}\right)$.

\subsection{Experimental Protocol}

The sixty mice, $22 \pm 2$ gm each, were divided into five groups (G1 was served as control; while G2, G3, G4 and G5 received 40; 500, 1000 and $1500 \mathrm{mg} / \mathrm{Kg}$ b.wt. respectively) All doses were calculated accurately and served accordingly. The first served as an untreated and therefore called control group while other four experimental groups were treated with the aspartame doses.

\subsection{Dissection of Animals}

After 5 weeks of daily treatment two animals out each group were cardiac perfused, under complete anesthesia with $10 \%$ formalin fixative in $0.1 \mathrm{M}$ freshly prepared phosphate buffer ( $\mathrm{PB}$ ) through the left ventricle (in vivo) and the right atrium was cut off to allow blood flow out [14]. Formalin fixative was injected into the left ventricle ( 2 mice/group) via a blunt end needle of a $50 \mathrm{~mL}$ size sy- 
ringe to avoid injuries to the heart and to perform unbiased experiments for both LM and TEM.

\subsection{Experimental Methods}

Phosphate buffer (PB) of $0.1 \mathrm{M}$ of $p \mathrm{H} 7.4$ was freshly prepared by mixing two different compounds of acid and basic sodium ortho-sulphate salts: 1) $\mathrm{Na}_{2} \mathrm{HPO}_{4} \cdot 2 \mathrm{H}_{2} \mathrm{O}$ and 2) $\mathrm{Na}_{2} \mathrm{HPO}_{4}$ [15]. The freshly made $10 \%$ formalin was prepared each time prior experiments as $10 \mathrm{gm}$ of formaldehyde dissolved in 100 $\mathrm{mL}$ of boiled distilled water then mixed with an equal amount of $0.2 \mathrm{M}$ of PB to bring the final molarity down to $0.1 \mathrm{M}$ of $\mathrm{PH} 7.4$ [16]. The liver samples were then placed in the same fixative for overnight fixation (post-fixation) at room temperature and processed for routine histological methods [17]. Series of ascending Ethanol $\left(\mathrm{C}_{2} \mathrm{H}_{5} \mathrm{OH}\right)$ alcohol concentrations i.e. $50 \%, 70 \%, 90 \%$ were prepared in the laboratory from fresh $100 \%$ absolute alcohol-free water to dehydrate the samples. Fresh paraffin wax was used throughout the whole work to embed the liver samples. Glass slide were washed and coated with using gelatin Chrome Alum Albumin (CAA) to guarantee sections stuck on the slides. Thin sections of $5 \mu \mathrm{m}$ were cut from each block and water bath was used to stretch the sections before collection on a clean glass slide. Paraffinized sections then were processed for routine light microscopy followed by being DPXed and examined using Olympus light microscopy.

\subsection{Transmission Electron Microscopy (TEM)}

Two animals from each group were anesthetized using tissue cloth socked with chloroform inside a firmly secured glass chamber. The anesthetized animals were then dissected out immediately; chest was open with extreme attention to avoid any bleeding which may bias the experiments. The body was then perfused by almost $20 \mathrm{~mL}$ of the $2.5 \%$ Gluteraldehyde fixative in $0.1 \mathrm{M}$ Phosphate Buffer $(\mathrm{PB})$ at PH 7.4 injected into the left ventricle using a cut-end needle fit on a 20 $\mathrm{mL}$ size syringe. The right atrium was incised to allow the blood to flush out to be washed off and replaced by the fixative [15]. The liver was flushed with the same fixative to guarantee a better fixation and to eliminate any subtle chance of artifacts. A few small $1 \mathrm{~mm}^{3}$ cubes of liver samples were cut off and kept in the same fixative within small jars for overnight post-fixation inside fridge. The following day, liver samples were washed out $(3 \times 10$ minutes $)$ using the same $\mathrm{PB}$, and were fixed with the secondary fixative of $1 \%$ of Osmium tetroxide $\left(\mathrm{OsO}_{4}\right)$ for 2 hours in the same PB. Samples were then washed $(3 \times 5$ minutes $)$ with $\mathrm{PB}$ followed washing with distilled water $(3 \times 10 \mathrm{~min})$ on shaker. Samples were then dehydrated using gradual ascending ethanol alcohol solutions started from $30 \%$, $50 \%$, and $70 \%$, for 20 minutes each followed in $100 \%$ for one hour ( 2 changes).

Samples then cleared using propylene oxide for one hour ( 2 changes) prior impregnating inside TAAB Resin-Propylene oxide ascending mixture (1:3, 2:2 then 3:1) before transferring them into fresh $100 \% \mathrm{TAAB}$ and then incubating 
them inside an oven fixed on $65^{\circ} \mathrm{C}$ temperature for 28 hours within appropriate plastic molds. Samples were then trimmed off, and ultra-thin sections ranged between $70-90 \mathrm{~nm}$ were cut by glass knives using Reichert Ultramicrotome. The samples were stained with Reynold stains for 20 minutes i.e. 5\% alcoholic Uranyl Acetate after filtration using Millipore filter, inside a blackened Petri dish to avoid the reaction of the light with the stain and formation of precipitants on the tissues [18]. Followed by the samples were washed out carefully with distilled water drops inside a Petri dish furnished with dentistry wax $(3 \times 3 \mathrm{~min})$.

Samples were then moved into another Petri dish on dentistry wax and stained with Lead Citrate (following filtration using Millipore filter fit on syringe) for another $20 \mathrm{~min}$. Sodium hydroxide $(\mathrm{NaOH})$ pellets were used to avoid formation and precipitation of Lead carbonates over the ultra-thin samples. The latter were then examined using Philips TEM and calibrated pictures of the hepatic tissues were taken accordingly.

\section{Results}

\subsection{Control Tissue}

The control hepatic tissues of mice demonstrated a thin fibrous capsule of connective tissue covering the whole liver with interconnected plates are made by grouping thousands of the cuboidal epithelial cells of the hepatocytes as plate-like bricks of a wall producing plates arranged radially around the central vein [Figure 1(a)]. Occasional small vacuoles around the central vein are seen within the cytoplasm of some hepatocytes [Figure 1(b)]. Neither lymph nodules nor diffused lymphocytes are detected within the parenchyma cells. From the centre to the periphery, the radiating plates of hepatocytes branches formed a rather sponge-like structure where sinusoids, the important microvascular components, does extend parallel to the plates leaving the spaces between them for blood to run freely. Hepatocytes showed a healthy and intact architecture with no piecemeal necrosis of liver cells.

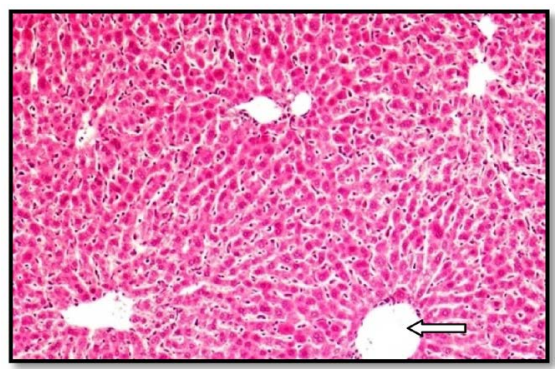

(a)

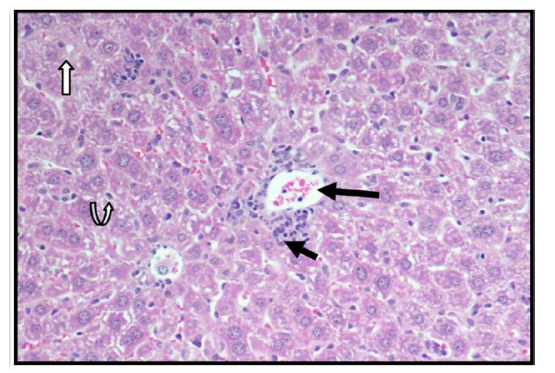

(b)

Figure 1. (a) and (b) Sections in the liver of control mice with central veins (white arrow), triad, intact sinusoids and hepatic plates running radially around the central vein (H \& E ×240) [1]; A $40 \mathrm{mg} / \mathrm{Kg}$ b.wt. APM hepatic tissue demonstrates early infiltration (short black arrow) around the central vein (long black arrow); small fatty droplets in the cytoplasm of the parenchyma tissues, scattered WBC in the extracellular matrix (white arrows) and fibroblast (H \& E $\times 480)[2]$. 


\subsection{Hepatic Tissues Treated with $40 \mathrm{gm} / \mathrm{Kg}$ Body Weight Dose}

Almost all hepatocytes showed a mild distention of portal tracts and parenchyma of the liver (lobular) with chronic inflammatory cells including lymphocytes and macrophages. An early development of fat droplets in their cytoplasm referred to a marked fatty infiltration in comparison with those of control and a mild distribution of lymphatic filtration around the central vein [Figure 1(b)]. A mild inflammatory cell infiltration was visible the portal tract. The sinusoids demonstrated a mild dilation with prominent blood vessels containing RBC with no increase in collagen fibers deposition.

\subsection{Hepatic Tissues Treated with Dose 500 gm/Kg Body Weight}

The severity of the lesions had increased in comparison with the lowest dose via infiltration of inflammatory cells around the central vein with development of giant cells which extended towards the parenchyma of the liver (lobular infiltration). A remarkable increase in infiltration of leucocytes around the central vein as well as development of early lymphoid follicles while fatty droplets continues increasing at this stage too. The portal tracts showed mild inflammatory cell infiltration and dilatation in the blood vessels; as well as development of a collection of various WBC around the central vein (Figure 2(a) and Figure 2(b)).

\subsection{Hepatic Tissues Treated with Dose 1000 gm/Kg Body Weight}

The impact severity had increased with higher doses by further increase in fatty droplets; early necrosis in hepatocytes began via loss of nuclei from some hepatocytes and early increase in intracellular matrix. A mild dilatation of the veins within portal tract with some fatty change of micro-canalicular pattern as well as very little inflammatory cells around bile ductless [Figure 3(a)].

\subsection{Hepatic Tissues Treated with Dose 1500 gm/Kg Body Weight}

An increase in lymphatic follicles around the central vein and between the intracellular matrix was noticeable (Figure $3(\mathrm{~b})$ ). Further WBC infiltration at

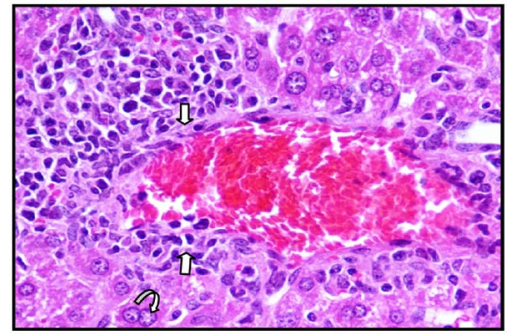

(a)

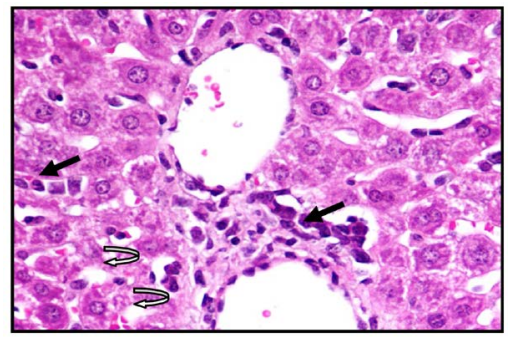

(b)

Figure 2. (a) and (b) Group-II (500 mg/Kg b.wt. APM) (a). demonstrates an increase in WBC infiltrations particularly around the central vein (cv) and development of early lymphoid follicles (white arrows). Note also increase in bi-nucleated hepatocytes and enlargement of nuclei in certain hepatocytes (bent arrow) (H \& E ×480) [3]; and increase in WBC infiltrations particularly around the portal vein (long black arrows) as well as development of early damaged hepatocytes (small white arrow) [H \& E ×550] [4]. 


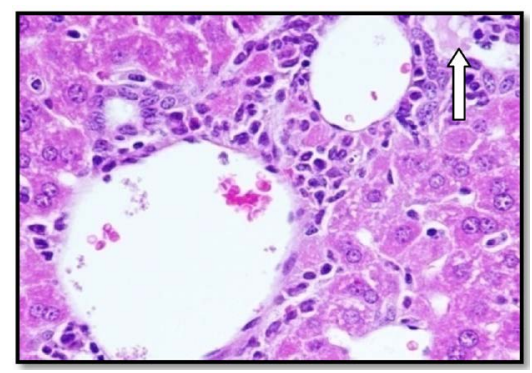

(a)

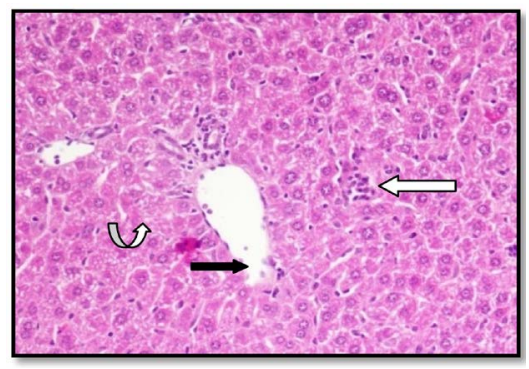

(b)

Figure 3. (a) and (b) Group-III (1000 mg/Kg b.wt. APM) demonstrates WBC infiltration at the triad and a few inflammatory cells around bile ductless. Early necrosis in hepatocytes via loss of nuclei from some hepatocytes and early increase in intracellular matrix (white arrow) and in fatty droplets from cytoplasm (H \& E ×480); and (b): Group-IV (1500 mg/Kg b.wt. APM) shows development in diffused lymphatic follicles around the central vein and between the intracellular matrix (white arrow). Some necrotic hepatocytes with lost nuclei (bent arrows) and some damage at the endolthelial epithelium of the central vein (black arrows).

the central vein and between the intracellular matrix and increase in necrotic hepatocytes via loss of nuclei were visible. Further increase of fatty droplets within cytoplasm and early increase in intracellular matrix of hepatic parenchyma and occasional damage at the endothelial layer of the central vein were detectable in comparison with earlier stages. The portal tract showed dilated veins containing RBC and a few inflammatory cells around other blood vessels. Some occasional apoptosis cells which lost their nuclei i.e. eosinophilic globules around veins were noticeable too.

\subsection{Ultrastructure of Hepatocytes in Control Mice}

The ultrastructural appearance of the hepatocytes in control mice showed an integrated architecture of both nuclear and cytoplasmic membranes with each individual hepatocyte showed a single rounded nucleus, usually centrally located. The chromatin is granular, with condensed heterochromatin at the periphery of the nucleus with more homogenous nucleoli presented a high electronic density with rough endoplasmic reticulum (RER) often arranged parallel to the nuclear membrane while the mitochondria were round to elongate and associated to the RER. Mitochondria of the hepatocytes had a typical homogenous population with classical ultrastructure containing few cristae and dense matrix. The different sized cytoplasmic vacuoles were distributed throughout the cytoplasm (Figure 4(a)).

\subsubsection{Hepatic Tissues of Mice Treated with $40 \mathrm{mg} / \mathrm{Kg}$ Body Weight APM} Some ultrastructural variations had appeared in comparison with those of the control. Early signs of disintegration were noticed in some hepatocytes with the lowest dose of the APM (40 mg/Kg body weight) via loose cytoplasm architecture while cytoplasmic organelles i.e. mitochondria, RER, Golgi apparatus as well as inclusions i.e. glycogen molecules were still intact at this stage. The 


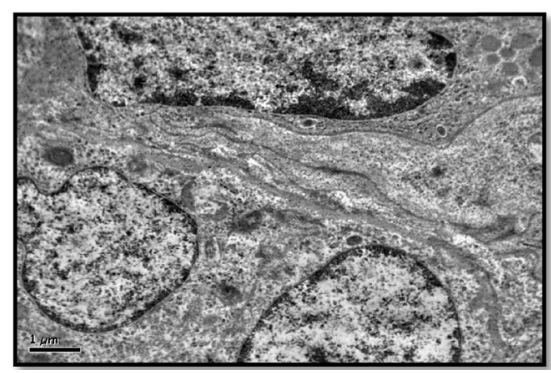

(a)

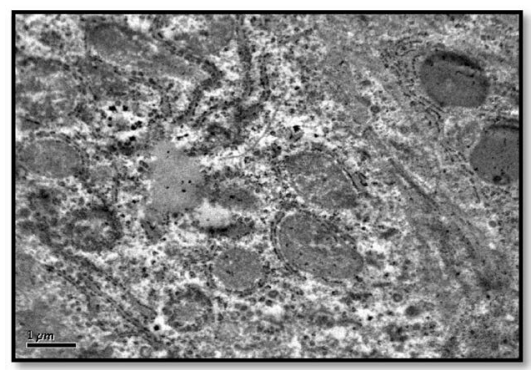

(b)

Figure 4. (a) and (b) Electron micrographs of control mice with a completely integrated architecture of hepatic tissue, spherical nuclei, intact nuclear membrane and intact inner cytoplasmic organelles. Two adjacent hepatocytes are seen with scattered glycogen particles inside the cytoplasm; and (b): A part of cytoplasm of a hepatocyte treated with 40 $\mathrm{mg} / \mathrm{Kg}$ b.wt shows some early indications of disintegration $(\times 4000)$.

endothelial cells showed no ultra-structural signs of damages (Figure 4(a)). Occasionally, some WBC (lymphocyte) was detected showing ultrastructural changes i.e. accumulation of vacuoles due to ruptured mitochondria (Figure $4(\mathrm{~b}))$.

\subsubsection{Hepatic Tissues Treated with Higher Doses (500 - 1500 mg/Kg Body Weight APM}

Early signs of disintegration in almost all hepatocytes were noticeable via development of lipofuschin and fatty droplets as well some ruptured mitochondria. These signs were specific to hepatocytes dosed with $500-1500 \mathrm{mg} / \mathrm{Kg}$ b.wt (Figure 5(a) and Figure 5(b)). The cytoplasmic organelles at the periphery of the nucleus had integrated configurations in mice treated with $500 \mathrm{mg} / \mathrm{Kg}$ body weight with an intact nuclear membrane; however, the outer skirts of the cytoplasm showed damages to mitochondria and development of fatty droplets. The cytoplasm of a hepatocyte treated with $1000 \mathrm{mg} / \mathrm{Kg}$ body weight APM showed development of clusters of small sizes of fatty droplets close to a still intact nuclear membrane in addition to various sized ruptured mitochondria. At the highest dose the cytoplasms of the hepatocyte contained predominantly increased fatty droplets and rupture more mitochondria while RER and glycogen molecules were unaffected (Figure 6(a) and Figure 6(b)). At this stage, only some nuclei showed irregularity in their nuclear membranes while the glycogen molecules were still unaffected.

\section{Discussion}

It is almost an impossible deal nowadays to follow a diet as completely free of sweeteners and/or other additives [19]. From industrial purposes, and due to the developments in life style, additives have become inevitably a must to achieve a few tasks i.e. extend shelf life and to improve flavor, color and texture or sweeten food (natural nutritive and artificial non-nutritive) which include antioxidants, preservatives, stabilizers, colorants, flavors, emulsifiers and sweeteners [20]. This had lead to expand uses of some daily consumed foods i.e. APM in our daily 


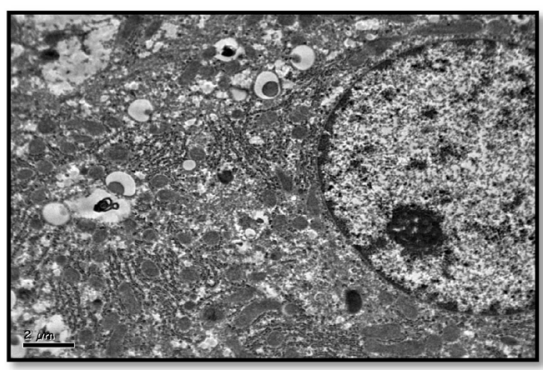

(a)

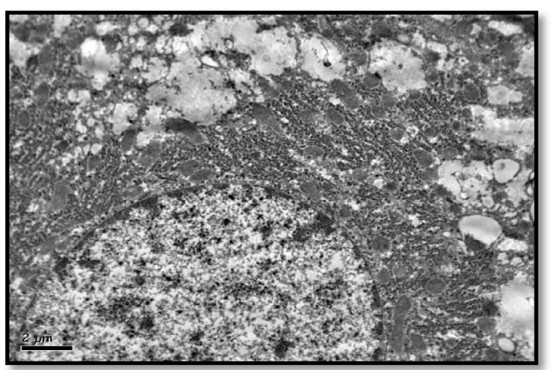

(b)

Figure 5. (a) and (b) Cytoplasm of a hepatocyte treated with $500 \mathrm{mg} / \mathrm{Kg}$ b.wt demonstrates the ultra structures of the cytoplasmic organelles at the perinuclear skirts which has integrated configurations with an intact nuclear membrane; however, the outer skirts of showed damages to mitochondria and development of fatty droplets (FD).

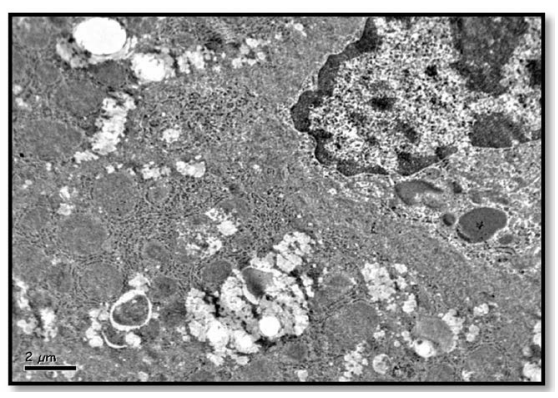

(a)

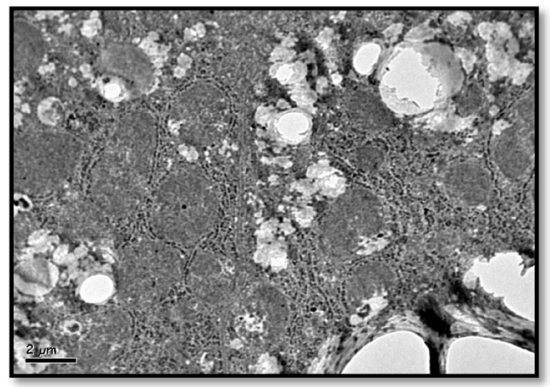

(b)

Figure 6. (a) and (b) Section through cytoplasm of a hepatocyte treated with $1500 \mathrm{mg} / \mathrm{Kg}$ body weight aspartame. Note the fatty droplets and the disintegration of some mitochondria while RER and glycogen molecules are unaffected. However, the nuclei showed irregularity while its membrane.

lives which, in turn, exerts extra risks to the human health. Results and conclusions are conflicting leading to two different opposing schools where one with safety consumption of the APM whiles another against. However, the latter is governed by two main factors i.e. the various scenarios in which these researches are conducted and the commercial greed by the manufactures who make a fortune every year. By all means, it has been announced safe and recommended by doctors to the diabetics at almost, every part of the world.

An early study of Schlatter and co-authors conducted on seven infant monkeys given Aspartame with milk showed that the high dose group did not consume the intended levels of APM leading to conclusion that the high-dose group actually ingested approximately as much Aspartame as the medium-dose group [21]. Luckily, this may indicate that the body has the capacity to absorb a certain limit of APM dose while higher doses may be discharged in certain way off the body or/and render, harmless. The vacuolated appearance of the cytoplasm in hepatocytes at light microscopic levels refered to accumulation of fatty droplets in the cytoplasm as well as damages to some mitochondria which, in this study, seemed dose dependant. Other cellular organelles i.e. nuclear membranes, glycogen droplets, smooth endoplasmic reticulum (SER) and rough endoplasmic 
reticulum (RER), Golgi apparatus were almost intact. Degeneration of mitochondria might have occurred which was interpreted due to the lack of energy [18].

The breakdown of fats into energy producing chemicals is an obligatory metabolism outcome of the liver via mitochondrial mechanisms. When mitochondria are rendered defective by aspartame poisoning, then fat cannot be processed to be used as energy store. The formation of fat from dietary calories proceeds because fat is built up directly in the cytosol of cells and accumulation is not dependent on mitochondrial function [22]. Therefore, following the storage of fats cells (lipocytes) in the hepatocytes it would fail to get rid of them despite how badly are needed to supply the body with energy. These victims literally cannot starve the fat off their bodies nor can get them out of their livers because of their compromised mitochondrial functional capacity leading to make matters worse as the mitochondrial DNA will severely be damaged. Methanol/formaldehyde poisoning occurring as the direct result of the obligatory metabolism of methyl radicals is the most common form of genetic damage, caused by formaldehyde cross linkage of DNA strains. The mitochondrial DNA is thousands times more vulnerable than nuclear DNA, and lacks the excellent repair mechanism that protects the integrity of nuclear DNA. The presently understood mitochondria DNA repair mechanisms are merely excisional, that is the DNA rendered abnormal by the aspartame/methanol poisoning is merely excised leaving the mitochondrial function at best insufficient, defective and incomplete [23] [24].

In addition, it produces inadequate and incomplete energy metabolism spins off highly damaging free radicals where methanol/formaldehyde poisoning is noted for this [25]. All these metabolites would affect the function of mitochondria rendering the hepatocytes, eventually, defective. Such defection would lead to accumulation of fatty droplets, vacuolation and perhaps cirrhosis on the long run. The fatty droplets in the present study might represent the onset of such defects being confirmed by TEM micrographs.

The results presented in this research revealed the short-term effects of APM on the hepatic tissues in mice where the histological structure of the liver of mice showed hepatocytes arrayed in cords, similar to what is found in many other mammals [26]. Some morphological changes have been induced in the hepatic tissues of the experimental animals. The histological examination of liver sections of mice administrated a low dose $(40 \mathrm{mg} / \mathrm{Kg}$ b.wt) and 3 high dose (500 $1500 \mathrm{mg} / \mathrm{Kg}$ b.wt) of APM revealed the portal triad was infiltrated with mononuclear inflammatory cells mainly lymphocytes and macrophages. Such a finding is in concomitant with those of rats treated by saccharine [27] and [28] in mice. The latter, however, used different doses ( 65 and $260 \mathrm{mg} / \mathrm{Kg}$ b.wt) and for longer term (30 weeks), but found similar results i.e. hypertrophy of hepatic cells, excessive vacuolation in the cytoplasm. Despite the difference in doses being used the mild cellular changes in the present results may therefore indicate the early alterations in the hepatocytes in comparison with previous works. It 
could also be interpreted that the cellular changes in hepatocytes may be both dose and time dependant. This is in concomitant with the role of liver in the metabolism of the APM leading to disturbance in the metabolism of the cell and resulting in morphologic abnormalities.

In acute alcoholic liver disease (alcoholic liver hepatitis) the liver biopsy had large fat droplets in the cytoplasm. The marked fatty liver infiltration developed in mice livers in almost all doses is similar, somehow to alcoholic liver disease [29]. These lipid droplets may aggregate and become very large or abundant, the fat-storing cells resemble adipocyte [22]. The vacuoles seen in the light microscopic sections indicated, for instance, to the development of fat droplets which might have dissolved out during tissue processing leaving empty holes. Similarly, in "Steato Hepatitis" characterized by an accumulation of fat in the hepatocyte resulting from ingestion of aspartame is focused in the mitochondria [30]. Mitochondria are the energy furnaces of the cell and aspartame metabolism leads to development of more toxic derivatives, formaldehyde and formic inside the mitochondria. As in all NutraSweet poisoning the formaldehyde and formic acid immediately attack the tissues they are generated in so a new co-existent plague of "anti-mitrochondrial antibody hepatitis" can be generated right along with the "Steato hepatitis" as the immune system reacts to the degenerated tissues [31]

Despite the variations in methodology of the experiments carried out regarding In summary, the destruction of the cytoplasmic organelles in the hepatocytes, accumulation of fatty droplets, vacuolation inside the mitochondria or ruptured mitochondria might be due to the toxic effects of APM via blood. This would lead to malfunction of the liver as a filtering organ in the body which may end up with cirrhosis and other liver disorders.

\section{Conclusion}

It is concluded that all doses of APM have acute effects on hepatocytes, and consequently to general functions of liver i.e. dose dependant destruction onto hepatocytes, development of lymphobia and the necrosis noted to the hepatocytes may lead, in turn, to further damage to the liver on the long run. Further long-term experiments are required to study the destructive effects of APM on these two vital tissues in the body.

\section{Conflicts of Interest}

The authors declare no conflicts of interest regarding the publication of this paper.

\section{References}

[1] Mitchell, H. (2006) Sweeteners and Sugar Alternatives in Food Technology. Wiley-Blackwell, Oxford, 94. https://doi.org/10.1002/9780470996003

[2] Burgert, S.L., Anderson, D.W., Stegink, L.D., Takeuchi, H. and Schedl, H.P. (1991) 
Metabolism of Aspartame and Its L-Phenylalanine Methyl Ester Decomposition Product by the Porcine Gut. Metabolism, 40, 612-618. https://doi.org/10.1016/0026-0495(91)90052-X

[3] Rencuzogullari, E., Tuylu, B.A., Topaktas, M., Ila, H.B., Kayraldiz, A., Arslan, M. and Diler, S.B. (2004) Genotoxicity of Aspartame. Drug and Chemical Toxicology, 27, 257-268. https://doi.org/10.1081/DCT-120037506

[4] EFSA National Experts (2010) Report of the Meetings on Aspartame with National Experts. https://en.wikipedia.org/wiki/Aspartame

[5] Health Canada (2012) Aspartame-Artificial Sweeteners.

[6] Food Standards Australia New Zealand (2015) Aspartame.

[7] Azad, M.B., Abou-Setta, A.M., Chauhan, B.F., Rabbani, R., Lys, J., Copstein, L., Mann, A., Jeyaraman, M.M., Reid, A.E., Fiander, M., MacKay, D.S., McGavock, J., Wicklow, B. and Zarychanski, R. (2017) Nonnutritive Sweeteners and Cardiometabolic Health: A Systematic Review and Meta-Analysis of Randomized Controlled Trials and Prospective Cohort Studies. Canadian Medical Association Journal, 189, E929-E939. https://doi.org/10.1503/cmaj.161390

[8] Santos, N.C., de Araujo, L.M., De Luca Canto, G., Guerra, E.N., Coelho, M.S. and Borin, M.F. (2017) Metabolic Effects of Aspartame in Adulthood: A Systematic Review and Meta-Analysis of Randomized Clinical Trials. Critical Reviews in Food Science and Nutrition, 58, 2068-2081. https://doi.org/10.1080/10408398.2017.1304358

[9] Henkel, J. (1999) Sugar Substitutes. Americans Opt for Sweetness and Lite. FDA Consumer, 33, 12-16.

[10] Mikkelson, D. (2015) FALSE: Aspartame-Sweet Poison. Snopes.

[11] Flaherty, M. (1999) Harvesting Kidneys and Other Urban Legends. Nurse Week.

[12] Butler, N. (2018) The Truth about Aspartame Side Effects. https://www.healthline.com/health/aspartame-side-effects\#outlook

[13] Rowan, A.J., Shaywitz, B.A., Tuchman, L., French, J.A., Luciano, D. and Sullivan, C.M. (1995) Aspartame and Seizure Susceptibility: Results of a Clinical Study in Reportedly Sensitive Individuals. Epilepsia, 36, 270-275. https://doi.org/10.1111/j.1528-1157.1995.tb00995.x

[14] Bazzaz, A.A. and Al-Johani, N.S. (2018) Acute Impact of Artificial Sweetener, Aspartame on Blood Parameter in Mice. Advances in Bioscience and Biotechnology, 9, 549-560. https://doi.org/10.4236/abb.2018.910038

[15] Bazzaz, A.A., Sulaiman, N.M. and Muhsin, S.S. (1989) Histopathological and Haematological Effects of Potassium Dichromate on Mice. 5th Sci. Conf. SRC, Baghdad, Iraq, 10-11 April 1989, 297-310.

[16] Bancroft, J.D. and Gamble, M. (2008) Theory and Practice of Histological Techniques. 6th Edition, Churchill Livingstone, Elsevier, London.

[17] Bazzaz, A.A. and Almanea, N.N. (2012) Assessment of the Acute Effects of Diesel Exhaust Emitted (DEE) on Blood Parameters of Guinea Pigs (Cavia porcellus). Journal of Environmental Science and Engineering, 5, 629-636.

[18] Alaa, A.F., Abdelgayed, S.S.A., El-Tawil, S.O. and Adel-Bakeer, M. (2016) Toxicological and Histopathological Studies on the Effect of Tartrazine in Male Albino Rats. Int J PharmacolSci, 10, 527-532.

[19] Abdullah, I.Z.A. (2002) Physiological Changes Induced by Long Term Administration of Saccharin Compared with Aspartame to Male Albino Rats. Egyptian Journal 
of Hospital Medicine, 8, 70-81.

[20] Duyff, R.L. (2002) American Dietetic Association Complete Food and Nutrition Guide. 2nd Edition, John Wiley \& Sons, Inc., Hoboken.

[21] Stoddard, M.N. (1995) The Deadly Deception. Compiled by the Aspartame Consumer Safety Network for Volumes of Available Published Information. ACSN, Dallas.

[22] Mischer, A.L. (2010) Junqueira's Basic Histology: Text and Atlas. 12th Edition, McGraw Hill Companies, New York.

[23] Da Silva, L.C., Carvalho, T.S., da Silva, F.B., Pires, R.F., Giugliani, R. and Pereira, M.L. (2000) Aspartame Loading Test in PKU Heterozygous Individuals Bearing Severe and Moderate Mutations. Clinical Genetics, 58, 86-88. https://doi.org/10.1034/j.1399-0004.2000.580118.x

[24] Jeffrey, A.M. and Williams, G.M. (2000) Lack of DNA-Damaging Activity of Five Non-Nutritive Sweeteners in the Rat Hepatocyte/DNA Repair Assay. Food and Chemical Toxicology, 38, 335-338. https://doi.org/10.1016/S0278-6915(99)00163-5

[25] Soffritti, M., Belpoggi, F., Manservigi, M., Tibaldi, E., lauriola, M., Falcioni, L. and Bua, L. (2010) Aspartame Administration in Feed Beginning Prenatally through Life Span, Induces Cancers of the Liver and Lung in Male Swiss Mice. American Journal of Industrial Medicine, 53, 1197-1206. https://doi.org/10.1002/ajim.20896

[26] Percy, D.H. and Barthold, S.W. (2001) Pathology of Laboratory Rodents and Rabbits. 2nd Edition, Iowa State University Press, Ames, 303-306.

[27] Hassanin, N.I. (1998) A Study on the Natural Nutritive and Non-Nutritive Sweeteners in Arts. Veterinary Medical Journal, 46, 133-153.

[28] Shakoori, A.R., Iqbal, M.Z. and Ali, A.A. (1995) Biochemical and Histopathological Effects of Saccharine on Mouse Liver. Pakistan Journal of Zoology, 27, 1-13.

[29] Sherlock, S. and Summerfield, J.A. (1979) A Colour Atlas of Liver Disease. Wolfe Medical Publication Ltd., London.

[30] Humphries, P., Pretorius, E. and Naude, H. (2008) Direct and Indirect Cellular Effects of Aspartame on the Brain. European Journal of Clinical Nutrition, 62, 451-462. http://www.feingold.org/Research/PDFstudies/Humphries2008.pdf

[31] De Vitro, R., Alisi, A., Masotti, A., Cecarrelli, S., Panera, N., Citti, A., Salata, M., Valenti, L., Fweldestein, A.E. and Nobilli, V. (2012) Markers of Activated Inflammatory Cells Correlate with Severity of Liver Damage in Children with Nonalcoholic Fatty Liver Disease. International Journal of Molecular Medicine, 30, 49-56. 